\title{
NARRATIVAS TRANSMÍDIA: ENTRE MULTILETRAMENTOS E LETRAMENTOS TRANSMÍDIA, O QUE LEVAR PARA A AULA DE LÍNGUAS?
}

\author{
TRANSMEDIA STORYTELLING: BETWEEN \\ MULTILITERACIES AND TRANSMEDIA LITERACY, \\ WHAT TO BRING TO LANGUAGE CLASS?
}

\section{Maria del Carmen de la Torre Aranda* Maximina Maria Freire}

\section{RESUMO}

Este artigo tem por objetivo apresentar e discutir o conceito de narrativa transmídia e investigar, entre multiletramentos e letramentos transmídia, que enfoque se mostra mais adequado à produção de narrativas transmídia. Iniciamos pela discussão da noção de narrativa transmídia, ilustrando-a e a situando na cultura de convergência. Em seguida, abordamos a questão dos letramentos e da transmídia para uma cultura de participação. Dando continuidade à argumentação, ressaltamos a pedagogia do pluralismo, destacando a perspectiva dos multiletramentos e, particularmente, as noções de design e agência. Finalizamos o artigo nos posicionando frente à dualidade que, então, se revela: escolher uma das visões de letramento ou, embasadas na perspectiva do pluralismo, optar pelas duas abordagens, percebendo-as como extensão, para responder ao questionamento motivador do presente artigo.

Palavras-chave: narrativa transmídia; letramentos para a educação em línguas; participação, pluralismo.

\section{ABSTRACT}

This article aims to present and discuss the concept of transmedia storytelling and to investigate, between multiliteracies and transmedia literacies, which approach is more appropriate to the production of transmedia storytelling. We begin by discussing the notion of transmedia storytelling, illustrating and situating it in the Convergence Culture. We then address the issue of literacies and of the transmedia for a Participatory Culture. Continuing our argumentation, we emphasize the pedagogy of pluralism, highlighting the perspective of multiliteracies and, particularly, the notions of design and agency. We end the article by taking a stand on the duality that then reveals itself: choosing one of the literacy views or, based on the perspective of pluralism, choosing both approaches, perceiving them as an extension, to answer the motivating questioning of this article.

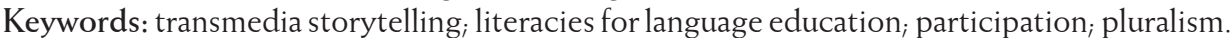

\footnotetext{
* Universidade de Brasília, UnB, Brasília, DF, Brasil. carmenarand@gmail.com.

Orcid: https://orcid.org/0000-0002-7900-6362

** Pontifícia Universidade Católica de São Paulo, PUC-SP, São Paulo, Brasil.mmfreire@uol.com.br. Orcid: https://orcid.org/0000-0002-7908-1143
} 


\section{INTRODUÇÃO}

[...] para aqueles que podem ver, a existência se passa em um rolo de imagens que se desdobra continuamente, imagens capturadas pela visão e realçadas ou moderadas pelos outros sentidos, imagens cujo significado (ou suposição de significado) varia constantemente, configurando uma linguagem feita de imagens traduzidas em palavras e de palavras traduzidas em imagens, por meio das quais tentamos abarcar e compreender nossa própria existência.

(Alberto Manguel)

Vivemos uma época em que, como nunca anteriormente, estivemos expostos a todos os tipos de informação, que nos atingem a todos os momentos, em quantidade absurda, por intermédio de recursos das mais variadas naturezas. Chegam-nos em partes, muitas vezes, cabendo-nos compor o todo por meio da conexão coerente daquelas partes nem sempre recebidas de forma ordenada. A exposição e edição das muitas informações recebidas passa a exigir a mobilização constante de competências já existentes e o desenvolvimento imediato de outras, inéditas, para que possamos lidar, simultaneamente, com variadas interfaces e seus diversificados input - impressos, sonoros, imagéticos, digitais - isolados ou de forma combinada. Leitura e escrita, como processos de codificação e decodificação de símbolos ortográficos e numéricos, apenas, já não bastam à plena comunicação; essas habilidades continuam sendo essenciais, mas tornaram-se básicas demais e, por isso, muito elementares e, muitas vezes, até banais. Precisamos sofisticá-las e transcendê-las para responder às sempre mutáveis interfaces e dispositivos digitais disponíveis à comunicação. Precisamos nos aprimorar e ir além de nossos limites para corresponder às conexões tecnológicas que se materializam todos os dias, gerando meios e possibilidades cada vez mais criativas de comunicação.

O desenvolvimento acima citado pode ser notado se contrastarmos, longitudinalmente, o significado das noções de alfabetização e letramento. A distância epistemológica existente entre os dois termos evidenciou a necessidade de um ajuste conceitual que, aplicado, expandiu a noção de processo (restrita ao primeiro), para a de processo contextualizado (como ressalta o segundo). Na falta de uma terminologia emergente do meio tecnológico, os mesmos conceitos foram adotados e, assim, inicialmente, evoluímos da alfabetização digital' (restrita ao domínio dos procedimentos instrumentais do computador) para o letramento digital (domínio instrumental de várias mídias associado ao domínio de práticas letradas).

1. Para maiores detalhes, ver: Sampaio, M.M. e Leite, L.S., Alfabetização tecnológica do professor. São Paulo: Editora Vozes. 2003. 
Como o desenvolvimento tecnológico acontece em velocidade exponencial, logo se verificou que o conceito de letramento digital era insuficiente para abarcar as habilidades necessárias para o uso de dispositivos tecnológicos de forma adequada e, especialmente, para utilizá-los com finalidades educativas. É nesse viés - e considerando a concepção de cultura de convergência, cultura de participação e cultura de conexão (Jenkins, 2008 [2006], 2013) - que este artigo se insere, alicerçado epistemologicamente nas noções de multiletramentos e letramentos transmídia, para embasar a discussão sobre narrativas transmídia e responder ao questionamento sinalizado no título deste artigo.

Nosso interesse pela narrativa transmídia para a educação em línguas reside justamente na possibilidade de explorar, juntamente com os estudantes de línguas, as formas que pode assumir o discurso narrativo ao longo de um processo de criação na língua alvo, cuja finalidade seja a de contar as suas próprias versões da história, isto é, das histórias que os rodeiam (as próprias e as alheias), das histórias que inspiram seus sonhos, que os fazem pertencer a uma cultura local que também dialoga com outras culturas representadas pela língua de aprendizagem.

Este artigo $^{2}$, portanto, apresenta e discute o conceito de narrativa transmídia (JENKINS, 2008 [2006]) para investigar, entre multiletramentos (GNL, 1996; COPE; KALANTZIS, 2009, 2015) e letramentos transmídia (JENKINS 2008 [2006]; SCOLARI, 2013), que abordagem se evidencia como mais propícia à produção de narrativas transmídia. Para atingir esse objetivo, iniciamos pela definição de narrativa transmídia, ilustrando-a e a situando na cultura de convergência (JENKINS, 2008 [2006]). Em seguida, abordamos a questão dos letramentos e da transmídia (JENKINS, 2008 [2006]; SCOLARI, 2016) para uma cultura de participação (JENKINS, 2009). Dando continuidade à argumentação, ressaltamos a pedagogia do pluralismo, destacando a perspectiva dos multiletramentos (COPE; KALANTZIS, 2009a; 2015; ROJO, 2012, 2013) e, particularmente, as noções de design e agência. Concluindo o artigo, respondemos ao questionamento que o originou, nos posicionando frente à dualidade que, então, emerge: escolher uma visão de letramento, ou, embasadas na perspectiva do pluralismo, optar pela adoção das duas abordagens, percebidas como extensão.

2. Artigo elaborado em coautoria com Maximina Maria Freire, fruto de pesquisa realizada sob sua supervisão, em 2019, durante estágio de pós-doutorado de Maria del Carmen de la Torre Aranda no Programa de Estudos Pós-Graduados em Linguística Aplicada e Estudos da Linguagem (LAEL) da Pontifícia Universidade Católica de São Paulo. 


\section{NARRATIVAS TRANSMÍDIA: DISTINTAS CAMADAS DE UMA MESMA HISTÓRIA}

Ao discutir a interpretação da imagem como uma narrativa, Manguel $^{3}$ (2001) argumenta que a construção de uma leitura desse tipo requer que se aplique à imagem aquilo que é próprio da narrativa: seu caráter temporal, sem o qual ela permanecerá sendo apenas uma imagem, associada ao espaço e à descrição que representa. A partir desse entendimento, o ensaísta argentino (MANGUEL, 2001, p. 28) afirma que sempre "construímos nossa narrativa por meio de ecos de outras narrativas". Tal asserção indica que a imagem torna-se narrativa não apenas quando lhe atribuímos uma temporalidade construída sobre o repertório iconográfico que acumulamos ao longo de nossas vidas, mas também os textos com que interagimos e outras circunstâncias de nossa vida social contribuem para essa construção.

A esse respeito, e refletindo sobre o ciclo de criação originado a partir de uma única obra, Manguel (2001, p.30) relata, em tom de anedota, a sugestão de seu conterrâneo Bioy Casares de se criar uma cadeia de obras de arte, partindo de um único poema do espanhol Jorge Manrique (séc. 15): "Bioy sugeriu a construção de uma estátua para o compositor de uma sinfonia baseada em uma peça sugerida pelo retrato de um tradutor dos 'Dísticos sobre a morte de seu pai'." Não sabemos se a empreitada foi levada adiante mas, se o tiver sido, terá certamente resultado em uma interessante narrativa transmídia - desde que respeitados, ao menos, dois dos princípios lógicos da transmídia tal como descrita por Jenkins (2008 [2006]): a conexão de todas as peças ao poema de partida por um gancho narrativo, expandindo seu tema, e a efetiva participação do público para manter viva a conexão narrativa, como veremos a seguir.

O conceito de narrativa transmídia foi originariamente introduzido por Henry Jenkins em um artigo publicado na Technology Review, em 2003, no qual esclarecia que "havíamos entrado em uma nova era de convergência de mídias que tornava inevitável o fluxo de conteúdos por meio de múltiplos canais ${ }^{4 \prime}$ (JENKINS, 2003, citado por SCOLARI, 2013, p.23). Esse conceito é aprofundado na obra Cultura da Convergência, de 2006 (lançado no Brasil em 2008), a partir de sua extensa pesquisa sobre como as transformações acarretadas pelo uso de mídias digitais alteram o modo como os conteúdos circulam nos nossos dias. Para compreendêlo, é importante, antes, situar o conceito no paradigma emergente da cultura da convergência, desenvolvido por Jenkins (2008 [2006], p. 41), para designar um

3. Agradecemos ao querido colega Cesário Alvim Pereira Filho pela sugestão da leitura.

4. No original: "hemos entrado en una nueva era de convergencia de medios que vuelve inevitable el flujo de contenidos a través de multiples canals". Todas as traduções neste artigo são de nossa responsabilidade 
processo em curso em nossas sociedades que "altera a relação entre tecnologias existentes, indústrias, mercados, gêneros e públicos".

A compreensão de que um processo de convergência dos meios de comunicação estava acontecendo foi enunciada, em 1983, pelo cientista político Ithiel de Sola Pool. O "profeta da convergência", como reconhecido por Jenkins (2008 [2006], p. 35), anteviu um processo de "convergência de modos" que romperia com as formas conhecidas em que operavam os meios de comunicação e de distribuição de serviços, e substituiria a lógica até então vigente do um para um (um meio de comunicação para um uso específico), por outra, em que um mesmo serviço seria oferecido por diferentes meios físicos (rádio, jornal, TV). Anos mais tarde, vimos que essa foi, efetivamente, uma consequência da digitalização das tecnologias - ou, talvez, da "plataformização de nossas sociedades" (VAN DIJCK et al., 2018) -, que permitiu que um mesmo conteúdo fosse distribuído e acessado por canais distintos, como acontece hoje, por exemplo, com a música que pode ser ouvida tanto em dispositivos mais antigos como os LPS e as fitas cassete, para fãs colecionadores, quanto em CDs, pela internet, em aplicativos de streaming ou em redes sociais, como o YouTube.

Tais transformações são melhor compreendidas se atentarmos para os dois sentidos embutidos no termo "meios de comunicação", conforme explica Jenkins (2008 [2006], p. 39), referindo-se a Lisa Gitelman: se considerados como sistemas de distribuição (tais como fitas cassete, CDs, fitas de vídeo VHS), os meios de comunicação são "simplesmente tecnologias" e, por isso, podem tornar-se obsoletos e ser substituídos por tecnologias mais recentes; contudo, em sua outra acepção, os meios de comunicação são também sistemas culturais associados a práticas sociais de consumo de conteúdos e, neste sentido, os meios sempre permanecem vivos para responder às demandas de comunicação e entretenimento das pessoas, ainda que mudem os suportes de distribuição. A esse respeito, Jenkins (2008 [2006], p. 40) chama a atenção para aquilo que designa como a "falácia da caixa preta", a previsão de que todos os conteúdos midiáticos seriam distribuídos em um mesmo e único suporte, uma caixa preta que funcionaria como uma espécie de controle central de todos os aparelhos e conteúdos. Embora alguns aparelhos possam hoje reunir várias funções, como os telefones celulares, entender que essa seria a convergência de mídias seria reduzi-la a uma mera questão tecnológica, sem levar em conta as práticas sociais em torno das mídias digitais. Na verdade, o que temos visto é, ao contrário, uma multiplicação dos suportes, que conversam cada vez mais entre si por meio da linguagem digital: o que converge são os conteúdos. 
Aí reside toda a ideia da convergência elaborada por Jenkins (2008 [2006], p.27). Trata-se de uma transformação cultural bem mais ampla, movida pela participação do público na circulação de conteúdos, como se percebe na definição que apresenta para esse conceito:

Por convergência, refiro-me ao fluxo de conteúdos através de múltiplos suportes midiáticos, à cooperação entre múltiplos mercados midiáticos e ao comportamento migratório dos públicos dos meios de comunicação, que vão a quase qualquer parte em busca das experiências de entretenimento que desejam. Convergência é uma palavra que consegue definir transformações tecnológicas, mercadológicas, culturais e sociais, dependendo de quem está falando e do que imaginam estar falando.

Para Jenkins (2008 [2006], p. 28), "a convergência ocorre dentro dos cérebros de consumidores individuais e em suas interações sociais com os outros", ou seja, com sua crescente participação nos espaços da web 2.0, as pessoas não apenas contribuem para fazer circular os conteúdos existentes, como também encontramse na posição de criar novos conteúdos, de desenvolver suas próprias interpretações para uma história (fanfics, mashups), expandindo assim, com suas próprias conexões e produções, uma narrativa inicialmente desenvolvida por uma indústria midiática. É nesse contexto de cultura participativa, em que as pessoas contribuem para a produção coletiva de significados ${ }^{5}$ (inteligência coletiva $a^{6}$, no sentido de Lévy, segundo Jenkins), que surge a narrativa transmídia ou transmidiática:

A narrativa transmidiática refere-se a uma nova estética que surgiu em resposta à convergência das mídias - uma estética que faz novas exigências aos consumidores e depende da participação ativa de comunidades de conhecimento. A narrativa transmidiática é a arte da criação de um universo (JENKINS, 2008 [2006], p. 47).

Uma das características centrais que distingue a narrativa transmídia de outras criações é o desdobramento da história em diferentes textos e mídias, construindo o universo narrativo a que se refere Jenkins. A trilogia Matrix é um exemplo claro desse tipo de universo: um filme original lançado em 1999, partes II e III lançadas no início dos anos 2000 e, no meio tempo, quadrinhos na web, um game para computador, um anime e um jogo online - todos produzidos pelas

5. Um exemplo dessa produção coletiva de significados, e que deu origem às conhecidas "Guerras de Potter", é a experiência do jornal escolar baseado na web The Daily Prophet, criado e mantido por jovens adolescentes norte-americanos, como uma forma de apropriação e de participação na cultura de Harry Potter. A esse respeito, sugerimos a leitura do capítulo Por que Heather pode escrever, em Cultura da Convergência (JENKINS, 2008).

6. Segundo ressaltam Gallo e Coelho (2012, p.51), a cultura da convergência surge, segundo Jenkins (2008), da relação de três conceitos presentes na sociedade de redes (CASTELLS, 1999 [1996]): a convergência dos meios de comunicação, a cultura participativa (BENKLER, 2007) e a inteligência coletiva (Lévy, 1998). 
mesmas idealizadoras, as irmãs Wachowski (JENKINS, 2008 [2006], p. 134). Cada uma das peças narrativas é autônoma, ou seja, para compreender uma, não deve ser imprescindível ter acesso a(s) outra(s), pois todas se conectam à narrativa inicial, como enfatiza Jenkins (2008 [2006], p.135):

Uma história transmidiática se desenrola através de múltiplos suportes midiáticos, com cada novo texto contribuindo de maneira distinta e valiosa para o todo. Na forma ideal de narrativa transmidiática, cada meio faz o que faz de melhor - a fim de que uma história possa ser introduzida num filme, ser expandida pela televisão, romances e quadrinhos; seu universo possa ser explorado em games ou experimentado como atração de um parque de diversões.

Esse desdobramento em múltiplos suportes obedece ao processo de elaboração estrutural da narrativa e, por isso, estabelece uma relação entre os textos e as mídias, envolvendo, necessariamente, três elementos característicos desse tipo de texto: serialidade, intertextualidade radical e multimodalidade. Esses elementos, conforme discutido por Jenkins, em Transmedia 202 (2011, s/p), não podem faltar para se caracterizar uma narrativa transmídia, do ponto de vista acadêmico. Vejamos cada um destes elementos, pois eles interessam particularmente ao debate em Linguística Aplicada, nas conexões que essa área estabelece com a educação em línguas.

Por serialidade, Jenkins (2011) entende o recurso de construção da narrativa de ficção que consiste em fragmentar um texto no tempo e alternar elementos episódicos e de dispersão, ou seja, combinam-se, por meio de ganchos narrativos, pequenas tramas pontuais, cujo desfecho se dá no próprio episódio, a elementos que se referem à trama maior da história. Jenkins lembra que, historicamente, os ganchos narrativos são apresentados no interior de um mesmo texto ${ }^{7}$, gerando no público um interesse em torno da trama e fazendo-os querer assistir aos próximos episódios ou rever algum deles para resgatar algum aspecto. Quando esses ganchos são colocados em textos independentes, veiculados em uma mesma mídia ${ }^{8}$, mas ainda estabelecendo conexões referentes à construção dos personagens, ao contexto em que vivem e à temática, temos o que Jenkins (2011) chama de intertextualidade radical. Por outro lado, se uma história é recontada em outro meio diferente daquele do texto original ${ }^{9}$, certamente ganhará novos sentidos derivados da interpretação de quem a realiza (cf. DENA ${ }^{10}$, citada por JENKINS, 2011), e derivados também das potencialidades oferecidas pelos modos semióticos particulares de representação

\footnotetext{
7. Como vemos nas novelas e nas séries online da Netflix.

8. Como, por exemplo, as versões 1 e 2 do filme Tropa de Elite, de José Padilha, ou as séries Carga Pesada e Castelo Rá-Tim-Bum, exibidos na TV aberta.

9. Por exemplo, na adaptação para o cinema de Amar, verbo intransitivo, de Mário de Andrade.

10. Christy Dena é pesquisadora do crossmedia storytelling.
} 
- multimodalidade (imagem, cores, enquadramento, gestos, som) - encontrados na nova mídia, mas sem necessariamente constituir-se em uma história transmídia.

Retomando a definição de Jenkins (2008 [2006], p.135), quando se refere ao fato de que "uma história transmidiática se desenrola através de múltiplos suportes midiáticos", podemos questionar se uma adaptação de determinado texto, realizada no contexto da aula de línguas, quando transposta para outra mídia pode ser considerada uma narrativa transmídia, e, ainda, se incluir uma parte da história que não seja realizada em meio digital (uma performance oral, por exemplo) poderia ter tal nomeação. Segundo Jenkins (2008 [2006], p. 169; 2011, s/p), a resposta seria afirmativa, desde que os desdobramentos da narrativa contivessem o que, para ele, é elemento fundamental na distinção entre adaptação e expansão: o acréscimo de uma "compreensão adicional" que conecta cada desdobramento à história principal, à medida que esta se move de uma mídia para outra, na forma do gancho narrativo, citado anteriormente. É vital, aqui, a necessária participação do público na narrativa transmídia: são as pessoas, em suas interações em rede, que vão descobrir os elos narrativos, os ganchos na forma de compreensão adicional e, desse modo, fazer da transmídia um verdadeiro universo narrativo. Na argumentação do autor (JENKINS, 2011, s/p.):

Para mim, um trabalho deve combinar intertextualidade radical e multimodalidade para os propósitos de compreensão adicional para ser uma história transmídia. É por isso que reduzir transmídia a 'uma história através de múltiplas mídias' distorce a discussão ${ }^{11}$ (grifo do autor).

De fato, se considerarmos apenas o adjetivo transmídia, estaremos esquecendo daquela que é sua própria essência: a narrativa.

Os elementos até aqui apontados como sendo fundamentais para a compreensão do que é a narrativa transmídia - como a fragmentação da história no tempo, seu desdobramento em diferentes suportes, as associações textuais que informam sobre a história, a diversificação de modos de representação - nos mostram que esse modo de contar histórias não só implica o uso de diversas mídias mas, sobretudo, que é transmídia porque emprega recursos de construção textuais próprios do tipo textual narrativo.

Para Santaella (2018, p. 78-79), esse é o ponto central da discussão: "os desdobramentos narrativos se constituem no DNA da narrativa transmídia. Um DNA que não dispensa o fato de que se trata de narrativa e não de outro tipo de

11. No original: "For me, a work needs to combine radical intertextuality and multimodality for the purposes of additive comprebension to be a transmedia story. That's why shortening transmedia to "a story across multiple media" distorts the discussion." 
discurso". A pesquisadora argumenta que a linguagem da narrativa é o que se sobressai na própria definição de transmídia: uma história que se conta, passando de um meio para outro, sempre mantendo "seu vínculo de continuidade com um canône mestre", um discurso que se constroi "no eixo da temporalidade", e cuja narratividade se estabelece na "sucessão de fatos", que é a base de toda narrativa. É por configurar-se na linguagem da narrativa, observa Santaella, que outros discursos (jornalístico, científico, técnico) poderiam até ser considerados "transmídia", se seu conteúdo efetivamente perpassar múltiplas mídias; no entanto, não se constituirão em narrativas transmídia, "pois lhes falta a 'cauda longa' da narrativa, ou seja, faltalhes a isca do fisgamento que destinos possíveis e imaginários - privilégios da narrativa - provocam no ser humano" (SANTAELLA, 2018, p. 79, grifo da autora).

Como ressaltado anteriormente, a construção de narrativas transmídia supõe o uso e o entrelaçamento de determinados elementos discursivos nos textos que as compõem - sejam eles produzidos para uma mídia digital, ou não. Assim, pensar as narrativas transmídia como prática de educação em língua estrangeira significa convidar os estudantes, no processo de criação, a identificar nos textos e nos recursos tecnológicos as potencialidades das diferentes linguagens e seus modos semióticos para a elaboração de sentidos e representações críticas das experiências que vivem em sociedade. Esta questão nos conduz ao diálogo com distintas propostas de letramentos a fim de identificar as bases que podem nos respaldar para tal abordagem pedagógica.

\section{LETRAMENTOS TRANSMÍDIA PARA UMA CULTURA DE PARTICIPAÇÃO}

A palavra que talvez melhor defina convergência é participação pois, como anteriormente exposto, na cultura da convergência, qualquer consumidor de cultura e comunidade de fãs (como os fãs de Star Wars, por exemplo) é continuamente convidado a participar da distribuição e da produção de conteúdos que circulam pelas redes da internet e da web. Contudo, não nos parece adequado tratar da cultura de convergência e, portanto, da participação, sem articulá-las à questão dos "letramentos que são necessários à participação em um processo de produção, distribuição e consumo de informação em multiplataformas de mídia" (GALLO; COELHO, 2011/2012, p.51).

Nas recentes pesquisas sobre letramentos digitais, a participação é vista como modo de entender o mundo conectado por redes. Nesse sentido, fica implícita a máxima: "consumir para entender, produzir para ser relevante" (danah boyd, citada por DUDENEY, HOCKLY, PEGRUM, 2016 [2013], p. 48), como modo de 
apropriar-se, ao menos, de parte desse mundo, uma vez que "[s]er letrado também quer dizer criar, contribuir e colaborar. Na era digital, a participação é componente do letramento genuíno" (GILLMOR, 2010, citado por DUDENEY, HOCKLY, PEGRUM, 2016 [2013], p. 48).

Embora a maior parte de jovens e adultos que chega à escola e à universidade, hoje, desempenhe cotidianamente uma série de práticas que se tornaram básicas na internet, sobretudo nas redes sociais ${ }^{12}$, isso não significa que eles estejam habituados a práticas de letramento que envolvam a realização de tarefas mais complexas na rede, associadas à leitura e avaliação crítica de fontes de informação, ou à produção de textos que explorem adequadamente as potencialidades dos modos de expressão da web.

Esse cenário, então, nos conduz a questionamentos intrigantes: Quais seriam os letramentos propiciados pelo desenvolvimento de narrativas transmídia no contexto da educação em línguas? Que formas de aprendizagem de línguas poderiam ser observadas se envolvêssemos os alunos em uma cultura de participação, ainda que localizada, de início, no contexto da educação formal? Se lembrarmos que na forma ideal de narrativa transmídia, cada meio faz o que faz de melhor, o trabalho colaborativo em torno da linguagem verbal, da imagem e do audiovisual, bem como da identificação das mídias mais adequadas para transportar determinados gêneros narrativos ocupará o primeiro plano quando a transmídia é tomada como prática de educação em línguas?

Algumas sugestões acerca do que se pode aprender no trabalho colaborativo em torno da linguagem são desenvolvidas por Jenkins (2008 [2006]), a partir de sua observação sobre o funcionamento das culturas participativas, como aquelas propiciadas pelas fan fictions. Nessas comunidades informais de aprendizagem - os chamados "espaços de afinidade" (cf. GEE, citado por JENKINS, 2008 [2006], p. 236) - pessoas de qualquer idade estabelecem relações interpessoais mais horizontalizadas do que aquelas da sala de aula. Dessa forma, a aprendizagem é distribuída de forma mais equilibrada, ou seja, são os próprios pares que ajudam os colegas com a redação dos textos, com o provimento de feedback e também os incentivam a testar novas formas textuais em espaços virtuais ainda não explorados (JENKINS, 2008 [2006], p. 238).

Essas práticas, segundo Jenkins (2008 [2006], p.235), contribuem para desenvolver habilidades de letramentos midiáticos ${ }^{13}$ como

12. Como subir um video ou foto, ou compartilhar um conteúdo recebido ou autogerado, por exemplo. 13. O autor não usa o termo letramentos transmídia. 
a capacidade de unir seu conhecimento ao de outros, numa empreitada coletiva; de compartilhar e comparar sistemas de valores, por meio da avaliação de dramas éticos; de formar conexões entre pedaços espalhados de informação; de expressar suas interpretações e sentimentos em relação a ficções populares por meio de sua própria cultura; e a capacidade de circular as criações pela internet, para que possam ser compartilhadas com outros.

As propostas de Jenkins encontram eco no entendimento de Scolari (2016, s/p.) sobre o que são os letramentos transmídia, ou seja, "um conjunto de habilidades, práticas, valores, sensibilidades e estratégias de aprendizagem e troca desenvolvidas e aplicadas no contexto da nova cultura colaborativa". Para Scolari (2016), os espaços informais de aprendizagem são também importantes para os letramentos transmídia, pois permitem agregar as habilidades que os estudantes desenvolvem em suas práticas sociais fora do espaço educacional que não estão apoiadas por livros didáticos ou outros suportes materiais.

Quando observamos as listas de competências que são sugeridas às escolas e universidades desenvolverem junto aos estudantes, seja por meio de livros ou em projetos político-pedagógicos, causa estranhamento a falta de uma orientação mais acurada sobre como colocar em prática os letramentos transmídia. Talvez esses letramentos venham a ganhar orientações de implementação mais específicas quando nos tivermos apropriado melhor também do contexto emergente da convergência. Contudo, talvez não seja essa a sua pretensão. Tomando como referência a reflexão de Scolari (2016, s/p), e relacionando-a à prática pedagógica de línguas, podemos dimensionar o letramento transmídia da forma que segue:

O letramento transmídia, entendido como um campo de investigação e ação em desenvolvimento, não deveria limitar-se a uma simples lista atualizada de competências. Assim como outras formas de letramento, o letramento transmídia deve ir além das dimensões cognitivas (saber) e pragmática (fazer): a dimensão emocional do sujeito é um elemento chave de qualquer processo de aprendizagem (Ferrés, 2014). O letramento transmídia, por outro lado, não deveria ser considerado uma alternativa ao letramento midiático, mas, sim, uma expansão em direção a novos territórios, concepções e práticas até agora muito pouco investigadas.

No atual contexto da educação em línguas em nosso país, seria impossível deixar de trazer os multiletramentos para esta reflexão. Embora pensada para trazer respostas às mudanças socioculturais nos países desenvolvidos de língua inglesa, a proposta dos multiletramentos teve grande repercussão na pesquisa brasileira em Linguística Aplicada, desde que aqui se tornou conhecida, em meados dos anos 2000. Como argumenta Rojo $(2012 ; 2013)$, é justamente pelo fato de chamar a atenção para dois tipos de multiplicidades que não necessariamente eram levados em conta na educação em línguas - a multicultural e suas "linguagens sociais", 
e a multimodal - que os multiletramentos se tornam relevantes. Nesse sentido, considera-os como uma evolução do conceito de letramentos (incluindo os múltiplos) sobre os usos sociais da escrita que já vinham se desenvolvendo no Brasil e no mundo anglo-saxão ${ }^{14}$, uma vez que ampliam o escopo desses estudos ao trazer para o centro da questão a necessidade de educar para a recepção e a produção de textos na sua pluralidade de formas contemporâneas. Apresentamos, a seguir, uma revisão da pedagogia dos multiletramentos, refletindo, particularmente, a respeito dos conceitos de design e agência, relevantes para o encaminhamento de nossa discussão.

\section{MULTILETRAMENTOS: A PEDAGOGIA DO PLURALISMO}

Elaborada pelos pesquisadores do Grupo de Nova Londres (GNL), em 1996, a pedagogia dos multiletramentos articulava sua proposta em torno de uma premissa inicial sobre o poder de transformação social da educação: "pedagogia é uma relação entre ensino e aprendizagem que cria o potencial para a construção de condições de aprendizagem que conduzam a uma participação social plena e igualitária' ${ }^{15 "}$ (GNL, 1996, p. 1). Naquela virada de século, marcada pelos crescentes processos de globalização e fluxos migratórios, e de comunicação por meio da internet e de mídias digitais, os pesquisadores do GNL entenderam que o ensino de língua(gem) e letramento só poderia contribuir para a plena participação social das gerações futuras nas esferas pública, comunitária e econômica de suas vidas se fosse embasado por uma abordagem pedagógica crítica que levasse em conta a multiplicidade de culturas, discursos, linguagens e formas textuais que emergia naquele momento, em decorrência dessas mudanças na sociedade.

Retomando uma imagem recorrente nos multiletramentos, "o desafio de aprender a comunicar nesse novo contexto era o de navegar as diferenças, ao invés de aprender a comunicar das mesmas formas ${ }^{16 "}$ (COPE $;$ KALANTZIS, 2015, p. 2; ênfase adicionada). Era preciso que as diferenças - multilíngues, étnicas, de

14. No Brasil, destacamos os estudos de letramentos desenvolvidos por Kleiman (1995) e Soares (2003), além de Rojo $(2009 ;$; 2012; 2013; 2015), dentre outros pesquisadores. No mundo anglosaxão, conforme lembram Cope \& Kalantzis (2015, p. 2), os multiletramentos inserem-se no contexto mais amplo de trabalhos em Novos Estudos de Letramento, desenvolvidos sobretudo por Brian Street (1984; 1995), James Gee (1996) e David Barton (1997).

15. No original: "Pedagogy is a teaching and learning relationship that creates the potential for building learning conditions leading to full and equitable social participation."

16. No original: The challenge of learning to communicate in this new environment was to navigate the differences, rather than learn to communicate in the same ways. 
culturas locais e subculturas dentro de uma mesma sociedade, de um lado, e a de linguagens e dos múltiplos modos semióticos de representação associados às tecnologias digitais e mídias de informação, de outro - fossem incorporadas às práticas de ensino e aprendizagem de letramentos, no plural, de maneira que os estudantes aprendessem a interagir e a negociar discursos segundo as novas formas de elaboração de sentidos que circulavam tanto fora quanto dentro do espaço da aula.

Como sabemos, essa abordagem do ensino foi materializada em torno da ideia de que a elaboração de sentidos - textos e discursos - deve ser concebida na aula como uma forma de design, ou seja, como uma forma dinâmica de representação em que os estudantes não mais se limitam a compreender e a reproduzir textos ditos por outros, geralmente vozes hegemônicas valorizadas por uma cultura erudita ou uma posição hierárquica de prestígio no mundo econômico e social. Ao contrário, devem se envolver como protagonistas em um processo cíclico de seleção, compreensão crítica e criação que resultaria em novos textos, espelhos de suas próprias visões de mundo e subjetividades. Assim, para os multiletramentos, o processo de design acontece, na aula, em três planos distintos de intervenção sobre os textos (COPE e KALANTZIS, 2009a, p. 175-178):

(1) o primeiro corresponde ao momento de explorar os textos/desenhos disponíveis (Available Designs) - é quando os estudantes fazem uma leitura crítica das múltiplas formas de representação empregadas por distintos locutores em distintas esferas da vida cotidiana, buscando identificar o gênero textual, os propósitos (sociais, políticos) dos discursos, e as relações de sentido criadas pela combinação entre linguagem escrita ou falada e imagem, característica dos textos digitais. É nesse momento que são exploradas as diversas formas de expressão das "linguagens sociais", como sugeria Gee (1996), vindas de grupos de afinidade, profissionais, étnicos, de subculturas;

(2) o segundo plano é o do desenbo de textos (Designing), o da criação - nesse momento, os estudantes exercem sua agência para criar novas representações de mundo tanto em processos de interpretação quanto de expressão de sua própria voz. A agência, neste plano do design, está ligada à compreensão que fazemos ao compor textos, de que as escolhas linguísticas e de outros modos associados à linguagem estabelecem relações de julgamento, de reprovação, de naturalização de comportamentos, de poder que talvez queiramos questionar e transformar por meio de novos designs; 
(3) o terceiro plano corresponde ao que fica como produto do desenho, os textos redesenhados (The Redesigned), textos recriados que carregam traços das subjetividades e visões de mundo daqueles que os produziram - esses novos textos vão, por sua vez, servir de recurso de aprendizagem, como novos textos (desenhos) disponíveis, para outras pessoas (estudantes) que participam do processo de transformação de representações de mundo.

Os três planos do design são realizados na aula por meio de quatro movimentos pedagógicos, inicialmente formulados pelo GNL (1996) como prática situada, instrução aberta, enquadramento crítico e prática transformada. Mais tarde, contudo, essa nomeação foi reformulada por Cope e Kalantzis (2009a), para os seguintes termos, respectivamente: experienciação, conceitualização, análise e aplicação. Quanto à terminologia diferenciada, os autores (COPE e KALANTZIS, 2015a, p. 4) asseguram que, o que conta nos multiletramentos, é a compreensão da aprendizagem como um processo de navegação constante e não linear, entre os quatro movimentos pedagógicos ${ }^{17}$.

Ilustrando essa metáfora, os diferentes planos do design sugerem navegar entre as experiências de aprendizagem que os estudantes vivenciam na escola e aquelas que trazem de suas práticas situadas fora da escola (prática situada/experienciação), navegar entre o empírico e o conceitual (instrução aberta/conceitualização), entre a análise funcional e a análise crítica dos textos (enquadramento crítico/análise), entre a criação e a aplicação criativa dos textos em contextos reais de comunicação (prática transformada/aplicação). Ao atravessar esse processo de representação, a ideia é que o estudante possa ser ajudado pelo professor a desnaturalizar o que já foi aprendido (GNL, 1996, p. 24) e, com distanciamento crítico, pessoal e teórico, abrir-se a novas leituras, a novas experiências de criação de textos, das quais ela/ele deve sair transformado, assim como suas visões culturais e de mundo. Referindo-se a Kress (2000; 2003), Cope e Kalantzis (2009, p.177-178) acrescentam:

$\mathrm{O}$ ato de representar para si mesmo o mundo e outras representações de mundo transforma o estudante. [...] À medida que o designer cria sentidos, eles exercem sua subjetividade no processo de representação, e como esses sentidos são sempre novos ("insights", "expressões", "perspectivas"), eles se recriam. O resultado de seu trabalho de representação e de seu exercício de subjetividade é uma subjetividade transformada $-\mathrm{e}$, portanto, aprendizagem (grifos dos autores). ${ }^{18}$

17. Não nos ateremos a aprofundar a discussão sobre os quatro movimentos da pedagogia dos multiletramentos pois escapam ao escopo do artigo.

18. No original: "The act of representing to oneself the world and others' representations of it transforms the learner him- or herself. [...] As the designer makes meanings, they exert their subjectivity in the representational process, and as these meanings are always new ("insights", 
Nessa breve revisão de multiletramentos, é possível observar, desde o texto seminal do GNL, de 1996, até os mais recentes de Cope e Kalantzis, de 2009 e 2015, o quanto a noção de agência vai se mostrando cada vez mais relevante para o projeto com o passar dos anos e a ênfase das mudanças sociais, também em decorrência do uso de mídias digitais. Agência aparece como o elemento que sustenta todo o processo de design e se conecta às ideias de criação, autoria, diversidade e transformação da educação em línguas, que estão na base da proposta epistemológica dos multiletramentos. A seguir, comentamos estas conexões, buscando refletir particularmente para as figuras do estudante e do professor e o que podem construir na aprendizagem de línguas a partir das potencialidades oferecidas pelas tecnologias e mídias digitais desde a perspectiva dos multiletramentos.

\subsection{Design e agência, criação e autoria}

Ao articular sua ideia central em torno da pedagogia do design como proposta para lidar com as diferenças, o GNL (1996) entendia que era necessário ir além dos tradicionais processos educacionais de reprodução para, assim, colocar os estudantes na posição de ativos criadores de sentidos (designers of meaning), com sensibilidade para compreender criticamente os discursos de poder e transformar os modos de representação de mundo existentes em novas maneiras de representação. Dessa prática de aprendizagem, nascem novos textos e discursos, ressignificados segundo os propósitos comunicativos, agência e subjetividades dos estudantes. Essencialmente, o que estavam propondo no manifesto programático de 1996 era que o papel da pedagogia fosse o de desenvolver uma "epistemologia do pluralismo", uma pedagogia de acesso ao capital simbólico da palavra e da cultura que tivesse valor real de participação, para os estudantes, nos emergentes contextos sociais de interação, uma pedagogia que tomasse suas diferentes linguagens, registros e discursos como recurso de aprendizagem, como ilustra o trecho a seguir (GNL, 1996, p.11):

Para ser relevantes, os processos de aprendizagem devem recrutar, ao invés de tentar ignorar e apagar, as diferentes subjetividades - interesses, intenções, comprometimentos e propósitos - que os estudantes trazem para a aprendizagem. O currículo agora deve lidar com diferentes subjetividades e as linguagens do seu público, discursos, e registros, e usá-los como recurso para a aprendizagem. [...] Esta é a base para uma pedagogia de acesso transformada - acesso ao capital simbólico com real valência nas realidades emergentes de nossos tempos. Tal

"expressions", "perspectives"), they remake themselves. The result of their representational work and their exertion of subjectivity is transformed subjectivity-and thus learning." 
pedagogia não envolve escrever sobre subjetividades existentes com a linguagem da cultura dominante. [...] Contudo, na realidade emergente há ainda déficits reais, tais como a falta de acesso ao poder social, à prosperidade, e a símbolos de reconhecimento. O papel da pedagogia é desenvolver uma epistemologia do pluralismo que promova acesso sem que as pessoas tenham que apagar ou deixar para trás as suas diferentes subjetividades. Esta deve ser a base de uma nova norma. ${ }^{19}$

Subjetividades só se exercem no discurso por meio da agência daquele que fala. Na pedagogia do design, o processo de construção, de representação e de transformação de sentidos por meio de textos, subjetividade e agência (que, entendemos, englobam as ideias de diferença e diversidade) são essenciais para que uma educação emancipadora em língua seja posta em prática. Agência é uma maneira de atuar sobre a elaboração de sentidos que imprime nos textos e discursos a subjetividade daquele que os (re)cria, segundo suas marcas culturais, identitárias, percepções e experiências de vida.

Ainda que os autores enfatizem o exercício e a marca da agência, sobretudo nos planos do desenho de textos, pois ela motiva a expressão de uma voz singular no momento da criação ${ }^{20}$ e do texto redesenhado ${ }^{21}$, em que a agência permanece como marca dessa singularidade misturada à polifonia dos textos recriados, entendemos agência como uma atitude do estudante que permeia necessariamente os três planos do design, pois ela determinará também, no processo heurístico de descoberta das formas e sentidos dos textos disponíveis (Available Designs), o que é relevante para o trabalho pedagógico (COPE e KALANTZIS, 2009a, p. 174). Afinal, não é disto que trata a prática situada como diálogo entre a educação e o mundo lá fora que representa os estudantes?

Quando revisitam a proposta inicial dos multiletramentos, uma década mais tarde, Cope e Kalantzis (2009a; 2009b) aprofundam o debate em torno da agência, chamando a atenção para a necessidade de a educação operar a mesma "troca na

19. No original: "To be relevant, learning processes need to recruit, rather than attempt to ignore and erase, the different subjectivities - interests, intentions, commitments, and purposes - students bring to learning. Curriculum now needs to mesh with different subjectivities, and with their attendant languages, discourses, and registers, and use these as a resource for learning. [...] This is the basis for a transformed pedagogy of access - access to symbolic capital with a real valence in the emergent realities of our time. Such a pedagogy does not involve writing over existing subjectivities with the language of the dominant culture. [...] Yet in the emergent reality, there are still real deficits, such as a lack of access to social power, wealth, and symbols of recognition. The role of pedagogy is to develop an epistemology of pluralism that provides access without people having to erase or leave behind different subjectivities. This has to be the basis of a new norm."

20. "Designing devolve agência humana e dinamismo cultural ao processo de elaboração de sentidos" (GNL, 1996, p. 26).

21. "O redesigned está baseado em padrões de sentido recebidos histórica e culturalmente; ao mesmo tempo é o produto único da agência humana: um sentido transformado" (GNL, 1996, p. 15). 
balança da agência" que já vinha acontecendo em nossas vidas pública, profissional e privada, em decorrência tanto das recentes mudanças nas formas de organização das sociedades quanto da lógica em que funcionavam as tecnologias e mídias digitais.

Muito do apontado por esses pesquisadores de dez anos para cá como sendo práticas letradas que realizamos nas mídias digitais online continua pertinente ainda hoje. É importante não negligenciar que aprimoramentos e avanços na configuração dos dispositivos tecnológicos são constantes e, por isso, nossa leitura de textos que falam sobre tecnologias deverá ser sempre dêitica, como sugerem Barton e Lee (2015, p. 21), pois apontam para momentos históricos específicos de nossa relação com as tecnologias. O que vale destacar, para esta discussão, são as mudanças na forma de interagir com e por meio dessas mídias e dispositivos, provocando alterações na nossa relação com a produção e o compartilhamento de informação e cultura. A possibilidade de interagir com TVs inteligentes e decidir a programação a que se deseja assistir; de ouvir música segundo a sua seleção pessoal em aplicativos de streaming como SoundCloud ou Spotify; de criar e compartilhar conteúdos multimodais em redes sociais da web 2.0 como Facebook, YouTube, Instagram, Twitter; de contribuir com a construção de conhecimento, adicionando informações e/ou algum verbete na Wikipedia, nos habituou, aos poucos, aos (hoje não tão novos) papéis de criadores, escritores, desenvolvedores, editores de conteúdos, com agência, sobretudo, para decidir sobre o quê e como queremos nos informar, e também contribuir para o caldo de cultura compartilhado nesses espaços online.

Nesse contexto, a noção de agência conecta-se fortemente às de criação e autoria. A antiga lógica de transmissão, característica das mídias de massa - assim como a da educação didática, em que o conhecimento fornecido pela instituição escolar era dado como definitivo - dá lugar a uma dinâmica de co-construção, característica de uma sociedade reflexiva em que a balança da agência está mais equilibrada entre as pessoas que, antes, ocupavam lugares definidos como audiência, de um lado, e produtores e difusores de cultura e conhecimento, de outro (COPE e KALANTZIS, 2009a; 2009b; KALANTZIS, COPE, 2015). Com a possibilidade de expressão e de participação aberta pelas tecnologias e mídias digitais, temos acesso à manifestação da diversidade de culturas e subculturas que nos compõem, agora com espaço para expressar seu canto, suas afinidades, diferenças, seus interesses, experiências, visões de mundo e suas linguagens sociais e seus discursos. Cope e Kalantzis (2009b, p.94) ainda observam: 
Uma maior margem para a agência sugere espaços autônomos onde se pode ser diferente e divergir. Agência mais diferença/divergência prefigura uma nova concepção expandida de direitos humanos. ${ }^{22}$

Que proposta, então, os multiletramentos trazem para o trabalho na aula de língua com relação, especificamente, às tecnologias e mídias digitais? Há um grande foco na multimodalidade dos textos que circulam pela web e internet, e na multiplicidade de caminhos de leitura oferecidos nesses espaços, sobretudo pelo crescente uso da imagem, entendidos como mudanças que desconstroem a complexidade antes mais atribuída ao texto escrito e nos colocam, como observam Cope e Kalantzis, referindo-se a Kress (2009a, p. 181), diante de uma maior complexidade da representação por meio do multimodal. Com o entendimento de que é necessário que os estudantes exerçam sua agência nos processos de representação, os multiletramentos propõem que se deva ensinar a ler e a escrever nesses ambientes, e a compreender como se dá a elaboração de sentidos em textos multimodais. Para isso, trazem a sinestesia como uma estratégia de aprendizagem em que os estudantes possam criar textos, alternando entre modos semióticos (escrito, visual, oral, imagens em movimento), testando combinações entre os modos, identificando quais modos servem melhor a determinada mensagem que se deseje transmitir e, desse modo, possam implicar-se em outras práticas de representação que não privilegiem apenas uma forma de expressão.

Uma extensão dessa proposta, trazida por Cope e Kalantzis, no texto New Media, New Learning (2009b), sinaliza possibilidades de mudanças no ensino, propondo ações específicas para estudantes e professores. Com relação aos estudantes, - além da possibilidade dada pelos recursos digitais de abordar aspectos distintos do conteúdo, em uma mesma aula, segundo o que cada qual já sabe ou deseja aprofundar - sugerem que registros de experiências de aprendizagem em portfólios digitais, produção de wikis, diários pessoais em blogs, gravação de vídeos digitais, por exemplo, sejam espaços que ajudem a criar mais conexões entre colegas, favorecendo a aprendizagem colaborativa e, assim, o intercâmbio de diferentes perspectivas do que estão construindo em seus designs. Quanto aos professores, sugerem que também sejam designers de pedagogia e de recursos digitais de aprendizagem, desde que utilizem as mídias digitais de modo diferente das abordagens didáticas tradicionais e possam, assim, contribuir para a criação e manutenção de uma "cultura de colaboração" entre docentes.

22. No original: "Greater scope for agency suggests autonomous spaces in which to be different, and to diverge. Agency plus difference/divergence prefigures a newly expanded conception of human rights." 
Considerando toda a argumentação apresentada, retomamos o questionamento que dá título a este artigo, parafraseando-o à luz dos componentes teóricos apresentados e discutidos: em tempos de convergência e de uma cultura de participação na produção dos conteúdos que circulam pela web e a internet, podemos afirmar que os multiletramentos fornecerão uma base teórico-prática de sustentação eficiente para a educação em línguas em nossos contextos educacionais?

\section{AFINAL, QUE LETRAMENTOS LEVAR PARA A AULA DE LÍNGUAS NUMA ABORDAGEM TRANSMÍDIA?}

Para responder ao questionamento motivador deste artigo e, especialmente, desta seção final, faremos um percurso recursivo, retomando os pontos de contato identificados entre as duas propostas de letramentos discutidas - multiletramentos e letramentos transmídia - com relação a objetivos, metodologia e tipo de relação que se estabelecem entre a aprendizagem e o mundo além do espaço educacional. Isso nos leva, inicialmente, a resgatar o momento histórico de cada uma das propostas.

A pedagogia dos multiletramentos, como sabemos, foi lançada em um manifesto programático, pelo Grupo de Nova Londres, um pouco antes da chegada dos anos 2000, período em que Jenkins (2008 [2006]) já pesquisava a cultura participativa. Sua obra sobre a cultura da convergência, publicada em 2006, chegou no Brasil em 2008, mais ou menos na mesma época em que os multiletramentos se tornaram mais conhecidos em nosso país também. No entanto, como toda nova proposta teórica tem seu tempo para ser apreendida e aplicada na prática educacional, o interesse pelo letramento transmídia e pela narrativa transmídia revela-se mais recente entre nós, como o atesta a publicação do primeiro volume dedicado a discutir o tema desde o ponto de vista de pesquisadores da educação brasileiros (cf. SANTAELLA, 2018). Pode-se dizer, então, que uma década separa esses estudos, entre produção, recepção e novas reflexões originadas a partir deles. Em dez anos, nas últimas décadas, certamente houve inúmeras mudanças nos contextos culturais, tecnológicos, políticos, econômicos e sociais que implicaram distintas abordagens da educação mediada por tecnologias.

Os multiletramentos, lançados no momento inicial dessas grandes mudanças, investiram em uma reflexão voltada sobretudo para uma educação que conduzisse a uma participação social plena e mais igualitária naquele contexto, com foco particular no tratamento das linguagens e na manifestação das subjetividades nos discursos criados em ambientes formais de aprendizagem. Do mesmo modo, a educação para a participação social plena é preocupação expressa nas propostas de 
letramentos midiáticos, assim como nas de letramentos transmídia que começam a ser compartilhadas no meio educacional. No White Paper 'Confronting the Challenges of Participatory Culture: Media Education for the 21st Century', publicado pelo Projeto New Media Literacies (JENKINS, 2009, s/p.), questões relativas a uma educação que valorize as habilidades necessárias para os estudantes participarem como trabalhadores e cidadãos do século 21 são colocadas em termos semelhantes àqueles postos pelos multiletramentos, relacionadas à resolução de problemas, à colaboração, criatividade e comunicação.

Nesse sentido, ambas as formas de letramento podem ser consideradas como propostas de desenvolvimento de habilidades sociais cujo objetivo é o de assegurar a plena participação dos jovens estudantes nas mais diversas esferas de atuação da vida pública, assim como de sua vida pessoal. Para isso, definem seu objeto de trabalho pedagógico com a linguagem em torno do design de textos e da narrativa transmídia. A metodologia do design de textos representa ainda hoje, uma abertura a linguagens que não era levada em conta nas práticas de educação em línguas, sobretudo naquelas que representam a diversidade cultural e de linguagens sociais dos falantes e usuários da língua alvo, no caso das línguas estrangeiras. No contexto sócio-histórico em que a proposta foi desenhada, era pertinente que seu foco com relação às tecnologias estivesse mais voltado para as formas de representação dos meios digitais que alteravam o uso da multimodalidade que era feita, até então, nos textos escritos.

Já os letramentos transmídia procuram nos levar a dar um passo adiante nas formas de representação, uma vez que seu contexto histórico é o da cultura de convergência, em que nos movemos com maior desenvoltura nos espaços online de interação, contribuindo para o fluxo de conteúdos de uma mídia para outra. Nesse sentido, os letramentos transmídia parecem chegar como uma expansão dos multiletramentos: enquanto estes colocam grande parte do seu foco na multimodalidade, conceito ligado a uma tradição da Linguística Aplicada que enfatiza a linguagem como prática social (MOITA LOPES, 2006) e as linguagens que compõem os textos (SANTAELLA, 2018, p. 72), os letramentos transmídia usam a compreensão da multimodalidade como ponte para criar os ganchos necessários entre um texto e outro que compõem uma narrativa transmídia. O passar de uma mídia a outra em uma mesma narrativa leva a uma exploração particular das linguagens, da multimodalidade e dos recursos digitais que envolve; leva a pensar em processos de construção textual como coesão e coerência que podem motivar os estudantes a ir além daquilo que podem fazer com os textos na perspectiva dos multiletramentos. 
Por fim, a questão das narrativas. Uma das questões levantadas pelos multiletramentos diz respeito ao uso da agência não como modo de fugir à realidade, como fazem algumas narrativas da web, como os games (COPE, KALANTZIS, 2009a, p. 173); mas, sim, como forma de preparar para ela, para que as pessoas assumam o protagonismo na produção de textos e de conhecimento e, desse modo, contribuam com vozes pluralistas para o processo de representação de mundo. As marcas pessoais da agência serão redistribuídas à medida que outras pessoas entrarem em contato com os textos redesenhados por esses letramentos. A questão da agência está, portanto, particularmente relacionada com as mudanças que a aprendizagem proporcionada por esses letramentos traz para o mundo além do espaço educacional.

Em sua análise dos letramentos midiáticos, Jenkins (2008 [2006], p. 328) destaca o papel das mídias digitais como recursos que nos oferecem oportunidades de participação para "reescrever as histórias que a cultura nos concede", e a educação midiática como uma forma de promover a participação social dos jovens na produção de cultura. Com as narrativas transmídia, parece-nos que a agência se expande ainda mais, distribuindo-se entre as mãos daqueles que se envolvem no processo de criação e redistribuindo-se nas mãos da audiência a cada vez que a transmídia entra em circulação e dependendo, unicamente, da audiência para que os elos narrativos que a compõem sejam reconstruídos.

Concluindo temporariamente, porém não esgotando o percurso de reflexão recursiva a que nos referimos no início desta seção, sentimo-nos melhor embasadas para afirmar que, quando se trata da sala de aula de línguas, entendemos que devemos abordar os dois tipos de letramentos: os multiletramentos e os letramentos transmídia, uma vez que ambos podem alicerçar momentos distintos da produção da narrativa transmídia: enquanto o primeiro (multiletramentos) nos auxilia na organização das práticas iniciais no trabalho intratextual em torno da multimodalidade e da criação a partir dos textos disponíveis, o segundo (o letramento transmídia) nos apoia no trabalho intertextual de concepção da narrativa como um todo, de identificação das potencialidades das mídias para transportar as partes esparsas do texto e criar os efeitos de serialidade desejados. Assim, com respaldo em Scolari, entendemos que os letramentos transmídia podem ser vistos não como uma alternativa aos multiletramentos, mas como uma importante expansão que pode oferecer uma oportunidade de levar os estudantes a lançar um novo olhar sobre a sua realidade local, à realidade de outras culturas onde se fala a língua estrangeira que aprendem, e às próprias tecnologias e aos mundos a que elas podem nos conduzir quando associadas à educação em línguas. 


\section{REFERÊNCIAS}

BENKLER, Y. (2007). The wealth of networks: How social production transforms markets and freedom. Yale University Press.

CASTELLS, M. (1996). A sociedade em rede. Era da informação: economia, sociedade e cultura, trad. Roneide Venancio Majer. São Paulo: Paz e Terra, 1999, 6a. ed. vol. 1.

COPE, B.; KALANTZIS, M. (2009a) Multiliteracies: New Literacies, New Learning. Pedagogies: An International Journal, p. 164-195. Disponível em <http:// newlearningonline.com/_uploads/pedagogiesm-litsarticle.pdf $>$. Acesso em: 12 fev. 2019.

COPE, B.; KALANTZIS, M. (2009b). New media, new learning. In: D. R. Cole e D. Pullen (Eds.), Multiliteracies in Motion: Current Theory and Practice. Londres: Routledge, 2009b, p. 87-104. Disponível em: <http://newlearningonline.com/_uploads/ colenewmedianewlearningchapter.pdf $>$. Acesso em: 12 fev. 2019.

COPE, B.; KALANTZIS, M. (2015). The Things You Do to Know: An Introduction to the Pedagogy of Multiliteracies. In COPE, B. e KALANTZIS, M. (Ed.), A Pedagogy of Multiliteracies: Learning By Design. Londres: Palgrave, p. 1-36. Disponível em: < http:// neamathisi.com/_uploads/Things_You_Do_to_Know_Cope_Kalantzis_2015. pdf $>$. Acesso em 12 fev. 2019.

DUDENEY, G., HOCKLY, N., PEGRUM. M. (2013). Letramentos digitais, trad. Marcos Marcionilo. São Paulo: Parábola, 2016, $1^{\text {a }}$ ed.

GALlO, P.; COELHO, M.G.P. (2011/2012). Aquisição dos letramentos necessários à cultura da convergência: a narrativa transmídia na escola. Quipus, ano 1, nº.1, p.51-62.

GRUPO DE NOVA LONDRES (1996). A Pedagogy of Multiliteracies: Designing Social Futures. Harvard Educational Review, vol. 66, n. 1, p. 1-31. Disponível em: < http:// newlearningonline.com/_uploads/multiliteracies_her_vol_66_1996.pdf $>$. Acesso em: 12 fev. 2019.

KALANTZIS, M.; COPE, B. (2015). Learning and New Media. In: Scott, D.; Hargreaves, E. (Eds.) The Sage Handbook of Learning. Londres: Sage, p. 373-387. Disponível em: <http://neamathisi.com/_uploads/Kalantzis_and_Cope_Learning_and_New Media_2015.pdf>. Acesso em: 12 fev. 2019. 
JENKINS, H. (2006). Cultura da Convergência, trad. Susana Alexandria. São Paulo: Aleph, 2008.

JENKINS, H. (2009). What is Learning in a Participatory Culture? (Part One). Confessions of an Aca-Fan, blog Henry Jenkins, maio, s/p. Disponível em: < http://henryjenkins. org/blog/2009/05/what_is_learning_in_a_particip.html $>$. Acesso em: $04 \mathrm{abr}$. 2019.

JENKINS, H. (2011). Transmedia 202: Further Reflections. Confessions of an Aca-Fan, blog Henry Jenkins, julho 2011, s/p. Disponível em: < http://henryjenkins.org/ blog/2011/08/defining_transmedia_further_re.html>. Acesso em: 04 abr. 2019.

LÉVY, P. (1994). A inteligência coletiva: por uma antropologia do ciberespaço. São Paulo: Loyola, 1998.

MANGUEL, A. (2001). Lendo imagens, trad. Rubens Figueiredo, Rosaura Eichenberg e Cláudia Strauch. São Paulo: Companhia das Letras.

MOITA LOPES, L.P. (Org.) (2006). Por uma Linguística Aplicada INdisciplinar. São Paulo: Parábola.

ROJO, R. (2012). Pedagogia dos multiletramentos: diversidade cultural e de linguagens na escola. In: Rojo, R.; Moura, E. (Org.) Multiletramentos na escola. São Paulo: Parábola, p. 11-31.

ROJO, R. (2013). Outras maneiras de ler o mundo. Educação no século XXI. Caderno Multiletramentos, v.3. São Paulo: Fundação Telefônica, p. 7-11. Disponível em: <http://fundacaotelefonica.org.br/wp-content/uploads/2013/03/caderno3 multiletramentos.pdf>. Acesso em: 12 fev. 2019.

SANTAELLA, L. (2018). A potência expansionista da narrativa. In: Santaella, L.; Massarolo, J.; Nesteriuk, S. (Org.), Desafios da transmídia: processos e poéticas. São Paulo: Estação das Letras e Cores, p. 66-83.

SCOLARI, C. (2013). Narrativas transmedia: cuando todos los médios cuentam. Barcelona: Centro Libros PAPF, S.L.U.

SCOLARI, C. (2016). Alfabetismo transmedia: Estrategias de aprendizaje informal y competencias mediáticas en la nueva ecología de la comunicación. Revista Telos, n. 103. Madrid: Fundación Telefónica, fev-mai. Disponível em: < https://telos. fundaciontelefonica.com/archivo/numero103/estrategias-de-aprendizaje-informal- 
y-competencias-mediaticas-en-la-nueva-ecologia-de-la-comunicacion/ $>$. Acesso em 11 abr. 2019.

VAN DIJCK, J.; POELL, T.; WAAL. M. (2018). The plataforma society: Public values in a connective world. Oxford: Oxford University Press.

Recebido: 20/11/2019

Aceito: 4/3/2020

Publicado: 5/8/2020 